\title{
Quantitative Structure Activity Relationship Studies of 4-Methyl-2-(p-Substitutedphenyl) Quinoline Derivatives as Potential Antifungal Agents
}

\author{
S. S. Chourasia ${ }^{1}$, P. K. Rahangdale ${ }^{2 *}$, F. Inam ${ }^{3}$ \\ ${ }^{1}$ Assistant professor and Head, Department of Chemistry, M. B. Patel College, Deori (M.S.), India \\ ${ }^{2}$ Associate professor and Head, Department of Chemistry, B. M. V. Amgaon (M.S.), India \\ ${ }^{3}$ Associate professor, Govt. Vidarbha Institute of Science and Humanities, Amravati (M.S.), India
}

\begin{abstract}
This research article reports the synthesis of a series of 4-methyl-2-(p-substitutedphenyl)quinoline derivatives which display potent antifungal activities. Moreover the potency of the synthesized compounds have been explored by means of Quantitative Structure Activity Relationship $(Q S A R)$ study carried out using regression analysis and statistically significant $\left(r^{2}\right)$ QSAR models. A number of descriptors were tested to adjudge a quantitative correlation between activity and structural features using training set and test set. It is evident from the QSAR study that majority of the antifungal activity is due to lipophilicity as well as cLogP influence on the biological activity. The results were interpreted on the basis of regression analysis. Since the developed QSAR models are found to be statistically significant and predictive, they can potentially be used for prediction of antifungal activities of new molecules before prioritization of their synthesis
\end{abstract}

Keywords-Quinoline derivatives, Descriptors, QSAR, Model validation, Antifungal activity, Regression analysis.

\section{INTRODUCTION}

Drug development is a cumbersome process which involve huge amount of investment in terms of money and time. It is estimated that it takes millions of dollars and around 15 years to transform a single potent molecule into effective drug. QSAR offers an alternative path to this process which offers quick and economical method of development of drug. QSAR has emerged as latest tool to design newer candidate for several therapeutic areas ${ }^{[1-}$
${ }^{3]}$.QSAR provides useful insights into the structural features which are responsible for biological activity and helps to generate a mathematical model which can predict activity of untested compounds quantitatively. These structurally related activities are commonly referred as structure-active relationship (SAR) ${ }^{[4]}$. The mathematical and statistical analysis of QSAR data finally help to reduce the number of molecules with the potent biological activity testing. QSAR study usually leads to predictive formula by correlation of physicochemical properties of a congeneric series with the biological activity ${ }^{[5]}$. Agrawal et al. ${ }^{[6-15]}$ have reported QSAR studies on different organic drug compounds. In the present investigation, QSAR study of a series of quinoline derivatives has been carried out to find out their antifungal potency. The study includes 8 descriptors which have been selected to develop the best fit model. The generated QSAR model was then used to predict the unknown antifungal activity of the test set compounds.

\section{EXPERIMENTAL}

All chemicals/reagents used throughout the investigation were of AR/chemically pure grade. Number of quinoline derivative were synthesised in accordance with the scheme represented in the Fig.1. The structures of the derivatives were confirmed with the help of techniques like ${ }^{1} \mathrm{H}$ NMR, IR and Mass spectroscopy. The synthesised quinoline derivatives were used as test set for the calculation of the antifungal activity. The details of the formulation of synthesised compounds are given in Table 1. 


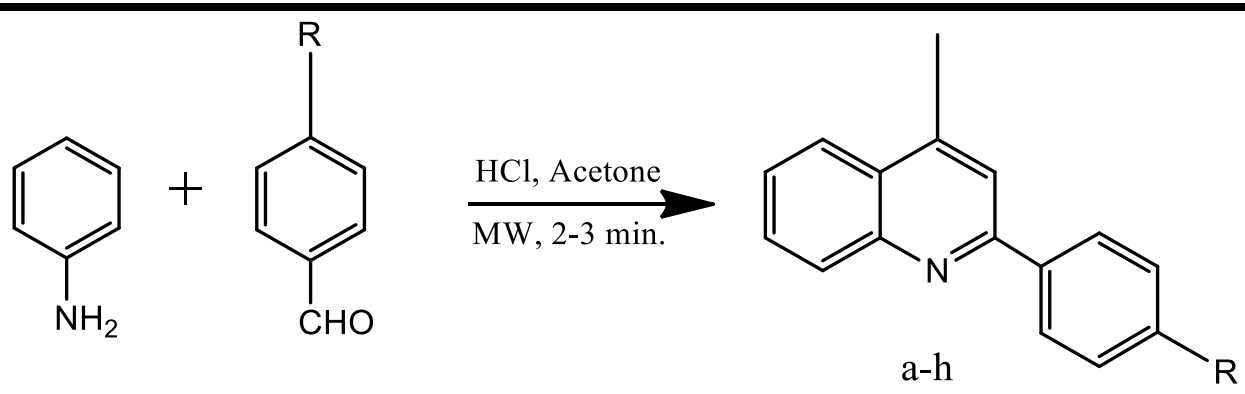

Fig.1: Synthesis of Test Set Quinoline compounds

\begin{tabular}{|c|c|c|c|c|c|}
\hline \multicolumn{6}{|c|}{ Table 1. Synthesised Test Set Quinoline compounds with their yield and Melting point } \\
\hline Sr. No. & Compound & $\mathbf{R}$ & Molecular formula & Yield (\%) & M.P. $\left({ }^{\circ} \mathbf{C}\right)$ \\
\hline 1. & $\mathrm{~A}$ & $\mathrm{H}$ & $\mathrm{C}_{16} \mathrm{H}_{13} \mathrm{~N}$ & 79 & $177-179$ \\
\hline 2. & $\mathrm{~B}$ & $\mathrm{CH}_{3}$ & $\mathrm{C}_{17} \mathrm{H}_{15} \mathrm{~N}$ & 74 & $183-185$ \\
\hline 3. & $\mathrm{c}$ & $\mathrm{OCH}_{3}$ & $\mathrm{C}_{17} \mathrm{H}_{15} \mathrm{NO}$ & 73 & $224-227$ \\
\hline 4. & $\mathrm{O}$ & $\mathrm{OH}$ & $\mathrm{C}_{16} \mathrm{H}_{13} \mathrm{NO}$ & 77 & $288-290$ \\
\hline 5. & $\mathrm{~N}$ & $\mathrm{NO}_{2}$ & $\mathrm{C}_{16} \mathrm{H}_{12} \mathrm{~N}_{2} \mathrm{O}_{2}$ & 72 & $237-239$ \\
\hline 6. & $\mathrm{f}$ & $\mathrm{Cl}$ & $\mathrm{C}_{16} \mathrm{H}_{12} \mathrm{ClN}$ & 86 & $218-221$ \\
\hline 7. & $\mathrm{~B}$ & $\mathrm{Br}$ & $\mathrm{C}_{16} \mathrm{H}_{12} \mathrm{BrN}$ & 87 & $248-252$ \\
\hline 8. & $\mathrm{COOH}$ & $\mathrm{C}_{17} \mathrm{H}_{13} \mathrm{NO}_{2}$ & 76 & $360-362$ \\
\hline
\end{tabular}

\section{QSAR studies}

\section{Generation of Training Data Set}

In the present investigation, a series of substituted quinoline based compounds reported by Sandhya Bawa et al. ${ }^{[16]}$ and B. C. Revanasiddapppa et al. ${ }^{[17]}$ were selected as training set. Total of 30 molecules with different substitution on the quinoline scaffold were selected as training set with their known biological activity with certain fungi. Structures of all the compounds determined by 2D-QSAR analysis and the antifungal activities in form of Zone of Inhibition ( $\mathrm{mm}$ ) have been presented in the Table 2 and 3. Structures of all compounds were sketched by chemdraw 8.0 software (chemoffice) ${ }^{[18]}$.

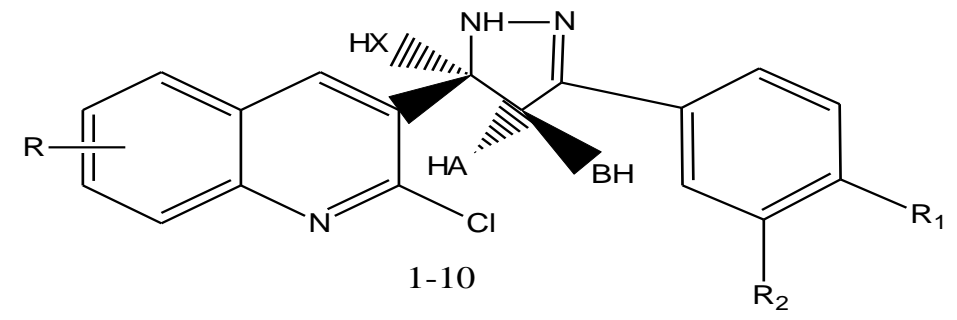

Fig. 2: Training data set molecues from 1-10

\begin{tabular}{|c|c|c|c|c|}
\hline \multicolumn{2}{|c|}{ Table.2: Composition and biological activity of training data set molecules from 1-10 } \\
\hline Comp. no. & $\mathbf{R}$ & $\mathbf{R}^{\mathbf{1} / \mathbf{R}^{\mathbf{2}}}$ & \multicolumn{2}{c|}{ ZOI (mm) } \\
\hline & & & $\mathrm{A}$. niger & C. albicans \\
\hline 1 & $\mathrm{H}$ & $\mathrm{Cl}$ & 11.53 & - \\
\hline 2 & $6-\mathrm{CH}_{3}$ & $\mathrm{Cl}$ & 10.69 & - \\
\hline 3 & $7-\mathrm{CH}_{3}$ & $\mathrm{Cl}$ & 12.16 & - \\
\hline 4 & $8-\mathrm{CH}_{3}$ & $\mathrm{Cl}$ & 10.58 & - \\
\hline 5 & $6-\mathrm{OCH}_{3}$ & $\mathrm{Cl}$ & 11.03 & - \\
\hline 6 & $\mathrm{H}$ & $\mathrm{OCH}$ & 9.16 & - \\
\hline 7 & $6-\mathrm{CH}_{3}$ & $\mathrm{OCH}_{3}$ & 7.86 & - \\
\hline 8 & $7-\mathrm{CH}_{3}$ & $\mathrm{OCH}_{3}$ & 8.66 & - \\
\hline 9 & $8-\mathrm{CH}_{3}$ & $\mathrm{OCH}_{3}$ & 7.63 & - \\
\hline 10 & $6-\mathrm{OCH}_{3}$ & $\mathrm{OCH}_{3}$ & 6.83 & - \\
\hline
\end{tabular}




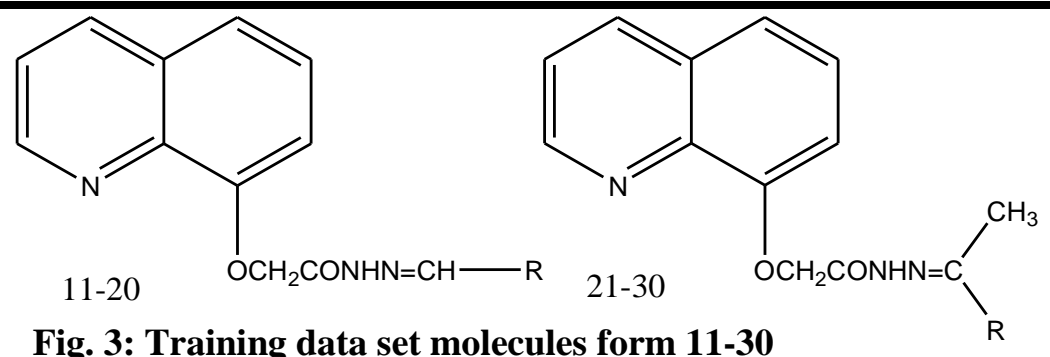

Fig. 3: Training data set molecules form 11-30

\begin{tabular}{|c|c|c|c|c|c|c|c|}
\hline \multicolumn{8}{|c|}{ Table.3: Composition and biological activity of training data set molecules from 11-30 } \\
\hline \multirow{2}{*}{$\begin{array}{c}\text { Comp. } \\
\text { no. }\end{array}$} & \multirow[t]{2}{*}{ R-CHO } & \multicolumn{2}{|c|}{ ZOI (mm) } & \multirow{2}{*}{$\begin{array}{c}\text { Comp. } \\
\text { No. }\end{array}$} & \multirow[t]{2}{*}{$\mathrm{R}-\mathrm{COCH}_{3}$} & \multicolumn{2}{|c|}{ ZOI $(\mathbf{m m})$} \\
\hline & & A. niger & C. albicans & & & A. niger & C. albicans \\
\hline 11 & $\mathrm{C}_{6} \mathrm{H}_{5}$ & 11 & 9 & 21 & $\mathrm{C}_{6} \mathrm{H}_{5}$ & 10 & 11 \\
\hline 12 & $\mathrm{p}-\mathrm{Cl}$ & 10 & 8 & 22 & $\mathrm{p}-\mathrm{Cl}$ & 11 & 11 \\
\hline 13 & $\mathrm{p}-\mathrm{OCH}_{3}$ & 10 & 10 & 23 & $\mathrm{p}-\mathrm{OCH}_{3}$ & 12 & 10 \\
\hline 14 & $\mathrm{p}-\mathrm{CH}_{3}$ & 9 & 11 & 24 & $\mathrm{p}-\mathrm{CH}_{3}$ & 10 & 9 \\
\hline 15 & $\mathrm{p}-\left(\mathrm{CH}_{3}\right)_{2} \mathrm{~N}$ & 11 & 10 & 25 & $\mathrm{~m}-\mathrm{NO}_{2}$ & 9 & 8 \\
\hline 16 & $\mathrm{o}-\mathrm{Cl}$ & 10 & 10 & 26 & $\mathrm{p}-\mathrm{NO}_{2}$ & 8 & 7 \\
\hline 17 & $\mathrm{~m}-\mathrm{Br}$ & 10 & 9 & 27 & $\mathrm{p}-\mathrm{NH}_{2}$ & 9 & 7 \\
\hline 18 & $\mathrm{p}-\mathrm{OH}$ & 09 & 10 & 28 & $\mathrm{p}-\mathrm{Br}$ & 10 & 10 \\
\hline 19 & $\mathrm{~m}-\mathrm{OH}$ & 11 & 11 & 29 & $\mathrm{p}-\mathrm{OH}$ & 11 & 11 \\
\hline 20 & $\mathrm{p}-\mathrm{Br}$ & 10 & 10 & 30 & o-OH & 10 & 11 \\
\hline
\end{tabular}

\section{Descriptor Calculation}

Various physicochemical descriptors like constitutional, molecular, steric, and electronic were calculated by the Datawarrier ${ }^{[19]}$ Software . The descriptors used to develop the model are listed and described in the Table 4.

\begin{tabular}{|l|l|l|}
\hline \multicolumn{2}{|c|}{ Table 4: Descriptors used for the training and test set } \\
\hline S. No. & Descriptor used & Symbol \\
\hline $\mathbf{1}$ & Total Molweight in g/mol; natural abundance & TMW \\
\hline $\mathbf{2}$ & cLogP; P; conc(octanol)/conc(water) & cLogP \\
\hline $\mathbf{3}$ & Total surface area(from polar and non-polar SAS Approximation) & TSA \\
\hline $\mathbf{4}$ & Druglikeness & Drug \\
\hline $\mathbf{5}$ & Lipophilic Ligand Efficiancy (LLE) & LLE \\
\hline $\mathbf{6}$ & Ligand Efficiency Lipophilic Price(LELP) & LELP \\
\hline $\mathbf{7}$ & Molecular shape Index & MSI \\
\hline $\mathbf{8}$ & Rotatable Bond Count & RBC \\
\hline
\end{tabular}

The descriptors calculated for the compounds and are given in the Table 5.

\begin{tabular}{|c|c|c|c|c|c|c|c|c|}
\hline \multicolumn{8}{|c|}{ Table 5. The value of descriptors calculated for the training set } \\
\hline S. no. & TMW & cLogP & TSA & Drug & LLE & LELP & MSI & RBC \\
\hline 1 & 376.673 & 5.3854 & 259.83 & 1.8974 & 3.6146 & 10.468 & 0.58333 & 2 \\
\hline 2 & 390.7 & 5.7293 & 272.09 & 1.8 & 2.9697 & 12.002 & 0.56 & 2 \\
\hline 3 & 390.7 & 5.7293 & 272.09 & 1.8 & 2.7936 & 12.25 & 0.6 & 2 \\
\hline 4 & 390.7 & 5.7293 & 272.09 & 1.8 & 2.6686 & 12.432 & 0.56 & 2 \\
\hline 5 & 406.699 & 5.3154 & 282.09 & 1.7961 & 2.9856 & 12.136 & 0.57692 & 3 \\
\hline 6 & 367.835 & 4.0334 & 273.51 & 1.7961 & 4.1884 & 9.2973 & 0.57692 & 4 \\
\hline 7 & 381.862 & 4.3773 & 285.77 & 1.7352 & 3.7776 & 10.564 & 0.55556 & 4 \\
\hline 8 & 381.862 & 4.3773 & 285.77 & 1.7352 & 3.7196 & 10.64 & 0.59259 & 4 \\
\hline
\end{tabular}




\begin{tabular}{|c|c|c|c|c|c|c|c|c|}
\hline 9 & 381.862 & 4.3773 & 285.77 & 1.7352 & 3.6685 & 10.707 & 0.55556 & 4 \\
\hline 10 & 397.861 & 3.9634 & 295.77 & 1.7961 & 4.0366 & 10.112 & 0.57143 & 5 \\
\hline 11 & 305.336 & 3.0925 & 244.11 & 4.1966 & 4.8661 & 6.5145 & 0.65217 & 5 \\
\hline 12 & 339.781 & 3.6985 & 259.53 & 4.2278 & 4.2223 & 8.1687 & 0.66667 & 5 \\
\hline 13 & 335.362 & 3.0225 & 266.37 & 4.2013 & 4.8636 & 6.9844 & 0.68 & 6 \\
\hline 14 & 319.363 & 3.4364 & 256.37 & 4.1258 & 4.4175 & 7.6545 & 0.66667 & 5 \\
\hline 15 & 348.405 & 2.9889 & 278.93 & 4.9362 & 4.835 & 7.2401 & 0.65385 & 6 \\
\hline 16 & 339.781 & 3.6985 & 259.53 & 4.2278 & 4.0974 & 8.2996 & 0.625 & 5 \\
\hline 17 & 384.232 & 3.8177 & 262.74 & 2.4066 & 3.9519 & 8.5961 & 0.625 & 5 \\
\hline 18 & 321.335 & 2.7468 & 250.46 & 4.1816 & 4.9979 & 6.2046 & 0.66667 & 5 \\
\hline 19 & 321.335 & 2.7468 & 250.46 & 4.1816 & 4.9744 & 6.2235 & 0.625 & 5 \\
\hline 20 & 384.232 & 3.8177 & 262.74 & 2.4066 & 3.8813 & 8.6749 & 0.66667 & 5 \\
\hline 21 & 319.363 & 3.0304 & 254.58 & 3.1347 & 4.6474 & 6.9049 & 0.625 & 5 \\
\hline 22 & 353.808 & 3.6364 & 270 & 3.1884 & 4.0212 & 8.6537 & 0.64 & 5 \\
\hline 23 & 349.389 & 2.9604 & 276.84 & 3.1842 & 4.6779 & 7.3453 & 0.65385 & 6 \\
\hline 24 & 333.39 & 3.3743 & 266.84 & 3.1347 & 4.2455 & 8.0698 & 0.64 & 5 \\
\hline 25 & 364.36 & 2.1088 & 278.25 & -1.944 & 5.4933 & 5.4595 & 0.59259 & 6 \\
\hline 26 & 364.36 & 2.1088 & 278.25 & -1.944 & 5.4762 & 5.4717 & 0.62963 & 6 \\
\hline 27 & 334.378 & 2.3531 & 263.1 & 3.1166 & 5.2155 & 5.6656 & 0.64 & 5 \\
\hline 28 & 398.259 & 3.7556 & 273.21 & 1.3447 & 3.7972 & 9.0613 & 0.64 & 5 \\
\hline 29 & 335.362 & 2.6847 & 260.93 & 3.143 & 4.8529 & 6.4906 & 0.64 & 5 \\
\hline 30 & 335.362 & 2.6847 & 260.93 & 3.143 & 4.8382 & 6.5033 & 0.6 & 5 \\
\hline
\end{tabular}

\section{Regression Analysis}

The linear regression was performed using the software $\operatorname{SPSS}^{[20]}$ by stepwise method. The best model derived from the regression analysis was used to predict the biological activity of the synthesised compounds. No outliers have been determined and the equations were derived using the entire training data set $(n=30)$. The summary of the model generated is given in the Table 6 .

\begin{tabular}{|c|c|c|c|c|c|}
\hline \multicolumn{7}{|c|}{ Table.6: Summary of the QSAR model generated by the regression analysis } \\
\hline Model & R & R Square & Adjusted R Square & Std. Error of the Estimate & $\begin{array}{l}\text { Durbin- } \\
\text { Watson }\end{array}$ \\
\hline 1 & 0.762 & 0.580 & 0.420 & 0.9830729 & 2.296 \\
\hline $\begin{array}{l}\text { Predictors: (Constant), Rotatable_Bonds, Total_Surface_Area, Druglikeness, Shape_Index, Total_Molweight, } \\
\text { LLE, cLogP, LELP }\end{array}$ \\
\begin{tabular}{l} 
Dependent Variable: Reported activity \\
\hline
\end{tabular}
\end{tabular}

\section{Validation test}

It has been proved that a high value of statistical characteristic ' $\mathrm{r}$ ', and ' $\mathrm{F}$ ' and low value of ' $\mathrm{s}$ ' need not be the criteria for a highly predictive model. Hence the models were converted in the form of equation by using the generated correlation values. The equations, then, were used to calculate the unknown activities of the test set compounds. The equations 1 and 2 are generated by the model. The comparison between the predicted and the experimental biological activities are graphically represented in Fig. 4.

QSAR model for A. Niger

Biological activity $(\mathrm{ZOI})=(18.354)+(-0.007 * \mathbf{T M W})+(4.359 * \mathbf{c L o g} \mathbf{P})+(0.132 * \mathbf{T S A})+(0.315 *$ Drug $)+(2.963 * \mathbf{M S I})+$ $(-0.419 * \mathbf{R B C})-----------(1)$

QSAR model for C. Albicans

Biological activity $(\mathrm{ZOI})=(18.354)+(-0.007 * \mathbf{T M W})+(4.359 * \mathbf{c L o g P})+(0.132 * \mathbf{T S A})+(0.315 *$ Drug $)+(2.963 * \mathbf{M S I})+$ 

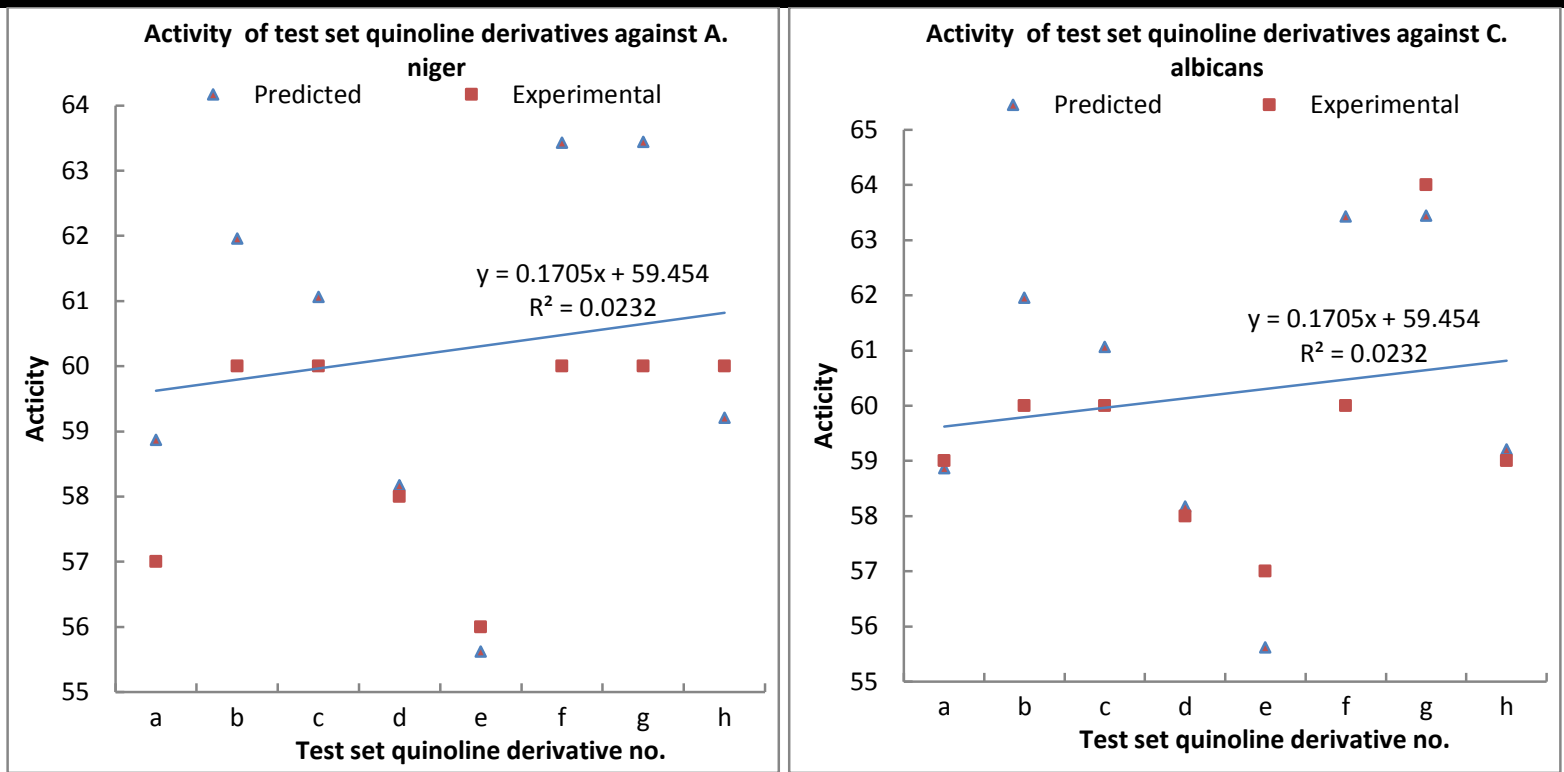

Fig. 4: Predicted and Experimental biological activities of test set quinoline compounds

\section{In-vitro antimicrobial activity}

The in-vitro antibacterial activity of the 2,4-substituted quinoline derivatives was investigated against two strains of fungi. Nutrient agar media was employed for the fungal growth. Fungal plates were incubated at $28^{0} \mathrm{C}$ for $5-7$ days. Two microbial strains i.e. A. niger and C. albicans were used in antimicrobial assay. Griseofulvin was used as standard. All the synthesised compounds were tested for their antifungal potency as compared to the reference drug within MIC range of $25-50 \mu \mathrm{g} / \mathrm{ml}$. The screening results have been tabulated in the Table 7.

\begin{tabular}{|c|c|c|c|c|}
\hline \multirow{3}{*}{ Compound } & \multicolumn{4}{|c|}{ Table.7: Antifungal screening of the synthesised quinoline derivatives } \\
\cline { 2 - 5 } & \multicolumn{3}{|c|}{ A. niger } & Predicted of zone of inhibition (mm) \\
\cline { 2 - 5 } & Predicted & Experimental & 58.87 & Experimental \\
\hline a. & 58.87 & 57 & 61.96 & 57 \\
\hline b. & 61.96 & 60 & 61.06 & 60 \\
\hline c. & 61.06 & 60 & 58.17 & 58 \\
\hline d. & 58.17 & 58 & 55.62 & 56 \\
\hline e. & 55.62 & 56 & 63.43 & 60 \\
\hline f. & 63.43 & 60 & 63.44 & 60 \\
\hline g. & 63.44 & 60 & 59.21 & 60 \\
\hline h. & 59.21 & 60 & & 62 \\
\hline Griseofulvin & 65 & & \multicolumn{2}{c|}{ C } \\
\hline
\end{tabular}

\section{RESULT AND DISCUSSION}

In the present study, eight descriptors were selected for the prediction of antifungal activity. The synthesised quinoline derivatives have been found to possess very good antifungal activity. The predicted and the experimental activities are in good agreement with each other. QSAR studies performed on these compounds have revealed that descriptors used to generate the model correlates the structure with the biological activity significantly.

\section{CONCLUSION}

Conclusively a series of 2,4-substituted quinoline derivatives have been synthesised and proved as potential antibacterial agents. The synthesised compounds have shown remarkable anti biological activity as confirmed from their high coefficient values. It can also be observed that the compounds bearing electron donating groups (b, $\mathrm{c}, \mathrm{f}, \mathrm{g}$ and $\mathrm{h}$ ) have found to possess little enhanced antifungal activity. The self developed QSAR models were found to be statistically significant as suggested from their regression analysis. Thus investigations presented in the research paper may have potential practical applicability in light of drug designing/pharmology. 
[1] Chhabria, M.T., Mahajan, B.M. and Brahmkshatriya, P.S. (2011) QSAR Study of a Series of Acyl Coenzyme A (CoA): Cholesterol Acyltransferase Inhibitors Using Genetic Function Approximation. Medicinal Chemistry Research, 20, 1573-1580. http://dx.doi.org/10.1007/s00044-0109413-3

[2] Buha, V.M., Rana, D.N., Chhabria, M.T., Chikhalia, K.H., Mahajan, B.M., Brahmkshatriya, P.S. and Shah, N.K. (2013) Synthesis, Biological Evaluation and QSAR Study of a Series of Substituted Quinazolines as Antimicrobial Agents. Medicinal Chemistry Research, 22, 4096-4109. http://dx.doi.org/10.1007/s00044-012-0408-0

[3] Tropsha, A. (2010) Best Practices for QSAR Model Development, Validation, and Exploitation. Molecular Informatics, 29, 476-488. http://dx.doi.org/10.1002/minf.201000061

[4] Hansch C., Acc. Chem. Res., 19, 392 (1993)

[5] Ertan, T., Yildiz, I., Tekiner-Gulbas, B., Bolelli, K., Temiz-Arpaci, O., Ozkan, S., Yalcin, I. and Aki, E. (2009) Synthesis, Biological Evaluation and 2DQSAR Analysis of Benzoxazoles as Antimicrobial Agents. European Journal of Medicinal Chemistry, 44, 501-510. http://dx.doi.org/10.1016/j.ejmech.2008.04.001

[6] Sharma S., Anita K., Shaik B., Ahmad I., Agrawal V.K., J. Engg. Sci. Mgt. Edu., 6 (II),153-157, (2013)

[7] Shaik B., Singh J., Agrawal V.K., Med. Chem, Res.,21,2097-2104 (2012)

[8] Singh J., Agrawal V.K., Khadikar P.V., J. Indian Chem.Soc., 85, 517-535 (2008)

[9] Agrawal V.K., Singh J., Singh S., Khadikar P.V., Oxid. Commu., 2-17 (2008)

[10] Agrawal V.K., Sharma R., Khadikar P.V., Oxid. Commu., 26,186 (2003)

[11] Agrawal V.K., Sinha S., Bano S., Khadikar P.V., Acta microbiologic., 48,17-26 (2001)

[12] Agrawal V.K., Shrivastava R., Khadikar P.V., Bioorg. Med. Chem., 9, 3287-3293 (2001)

[13] Agrawal V.K., Sharma Ruchi., Khadikar P.V., Bioorg. Med. Chem.,10,1361-1366 (2002)

[14] Agrawal V.K., Sinha S., Khadikar P.V., Indian Journal chem., 393, 472-474 (2000)

[15] Sinha S., Bano S., Agrawal V.K., Khadikar P.V., Oxid. Commun., 22, 479-486 (1999)

[16] Bawa S., Kumar S., Drabu S., Panda B. P., Kumar R. , J. pharm Bioall Sci (2009) vol 1 issue 1 32-36

[17] Revanasiddappa B C, Subrahmanyam, E V S, Satyanarayana, D, Thomas John, int. jou. of chemtech research, (2009), vol1, issue Druglikeness, 1100-1104

[18] www.cambridgesoft.com

[19] www.openmolecules.org

[20] http://bioinformatikz.googlepages.com 